University of Nebraska - Lincoln

DigitalCommons@University of Nebraska - Lincoln

Faculty Publications, UNL Libraries

Libraries at University of Nebraska-Lincoln

2020

\title{
A Brief History to the Future of Open Access
}

Margaret Mering

University of Nebraska - Lincoln, mmering1@unl.edu

Casey D. Hoeve

University of Nebraska-Lincoln, achoeve@unl.edu

Follow this and additional works at: https://digitalcommons.unl.edu/libraryscience

Part of the Library and Information Science Commons

Mering, Margaret and Hoeve, Casey D., "A Brief History to the Future of Open Access" (2020). Faculty Publications, UNL Libraries. 409.

https://digitalcommons.unl.edu/libraryscience/409

This Article is brought to you for free and open access by the Libraries at University of Nebraska-Lincoln at DigitalCommons@University of Nebraska - Lincoln. It has been accepted for inclusion in Faculty Publications, UNL Libraries by an authorized administrator of DigitalCommons@University of Nebraska - Lincoln. 


\title{
A Brief History to the Future of Open Access
}

\author{
Margaret Mering and Casey D. Hoeve, Contributor
}

\begin{abstract}
Metadata Quality Librarian, Scholarly Communications Unit, Love Library, University of Nebraska-Lincoln, Lincoln, Nebraska, USA; Head of Content \& Collections, Love Library, University of Nebraska Lincoln Libraries, Lincoln, Nebraska, USA

Contact - Casey D. Hoeve achoeve@unl.edu Head of Content \& Collections, Love Library, University of Nebraska Lincoln Libraries, P.O. Box 884100, Lincoln, NE 68588-4100, USA.
\end{abstract}

\begin{abstract}
There are many challenges when attempting to understand the current open access environment, and the frameworks and best practices that are driving the movement forward. Collection development and scholarly communications have become a partnership of blurred lines, as paid subscriptions must be managed in parallel with open access content. Given the rapid pace of change, the coverage of the past 20 years of open access is the most relevant to grasp present conditions and the trajectory of the future of open access initiatives. Within that time frame, important milestones, advocacy groups, open access models, and sprouting enterprises will illustrate what is meant when open access is discussed.
\end{abstract}

Keywords: Article processing charges (APC), open access (OA), open educational resources (OER), scholarly communications, serials crisis, transformative agreements

Published in Serials Review 2020, VOL. 46, NO. 4, pp 300-304.

doi:10.1080/oo987913.2020.1850041

Copyright (C) 2020 Margaret Mering and Casey D. Hoeve. Published with license by Taylor

\& Francis Group, LLC. Used by permission. 


\section{Introduction}

In 2019, the Massachusetts Institute of Technology (MIT) Libraries and the MIT Committee on the Library System partnered to form the Ad Hoc Task Force on Open Access to MIT's Research and provided recommendations to create the "MIT Framework for Publisher Contracts" (MIT Ad Hoc Task Force, 2020). The framework outlined ways in which libraries should aspire to negotiate with information vendors, with the optimal goal of making university authored publications open access (OA) and freely available to the public. How this developed is based upon historical milestones, both failures and successes, to help ensure libraries and information access remain sustainable well into the future.

\section{Historical milestones}

Open access maintains a dynamic history that has proved flexible and adaptable to modern-day publishing practices. Originally referred to as the Free Online Scholarship Movement, major open access milestones have been documented over the last 50 years (Suber, 2009), illustrating the longevity of the principles advocating for the free distribution of knowledge. However, sifting through the multitude of

projects and initiatives can be overwhelming, and obscure the picture of how we view open access in the modern sense.

For the sake of relevance, the last 20-years of open access milestones convey lingering and future aspirations that best shed light on the present scholarly environment. In order to answer the contemporary question, "what is" open access, it is important to understand "why" it exists, and how libraries have become major stewards of the movement. In this context, one of the most important catalysts driving open access is the serials crisis: the inability to subscribe to journals and databases from information vendors that increase their prices beyond what libraries can sustainably afford.

In response to the serials crisis, between 2002 and 2003, the Budapest Open Access Initiative, the Berlin Declaration on Open Access to Knowledge in the Sciences and Humanities, and the Bethesda Statement of Open Access Publishing were announced (Suber, 2015). These 
statements encouraged universities and scholarly organizations worldwide to publicly advocate for, and support the active implementation of open access policies in their institutions. Hundreds of universities and scholarly associations signed the declarations; however, other than some discipline specific open access databases available, larger-scale, institutional experiments and metrics for success were not widely available to serve as a reliable template.

In 2015, the Max Planck Society (MPS) for the Advancement of Science conducted a study to determine if institution-wide open access could be achieved. Their hypothesis was based around author processing charges (APCs), fees that can be paid by an author to make a journal article open access, rather than access through costly subscriptions or interlibrary loan. Through their study of the MPS' own subscriptions, it was suggested that if universities paid APCs for their own faculty publications, open access would be extensive enough to enable the cancelation of all subscriptions (Schimmer et al., 2015). In 2016, the "Pay it Forward Project" attempted to replicate these results among major universities in the United States, and it was found that "library budgets alone are unlikely to be sufficient to fund publishing activities through APCs (University of California Libraries, 2016). Lacking a viable model, new strategies needed to be developed to successfully enact open access measures in the scholarly publishing environment.

In 2018 and 2019, major shakeups of the scholarly publishing world occurred as the result of another major serials crisis. While many universities have been recorded for canceling large journals packages, known as big deals (SPARC*, 2020) since 2003, major European and United States consortia took monumental steps toward challenging unsustainable prices charged by publishers. In 2018, more than 800 German and Sweden academic institutions could not reach an agreeable subscription deal with Elsevier, including open access stipulations, leading to loss of access (Kwon, 2018). In 2019, failed negotiations between the University of California System and Elsevier caused the University of California to cancel its journal subscriptions with Elsevier system-wide (McKenzie, 2019). These decisions are being carefully observed by many other libraries to determine the effects on resource access, and whether they can rely on alternative resource provision networks, such as institutional repositories and interlibrary loan. 


\section{Stewards and shepherds of the open access framework}

Open access would not remain among the forefront of important library issues if not for the many organizations dedicated to advocacy and vigilance of publishing models. Organizations such as SPARC* (Scholarly Publishing and Academic Resources Coalition), The Directory of Open Access Journals (DOAJ), The Open Scholarly Publishers Association, the Confederation of Open Access Repositories (Royster, 2016), and cOAlition S. These organizations continue to expand open access initiatives and services as the publishing industry evolves. Consortia, or groups of libraries partnered together for resource contract negotiations and some of those projects are also vital to the open access arena. Major groups such as the Big Ten Academic Alliance, the Greater Western Libraries Alliance, the University of California System, and Projekt Deal have made strong attempts to negotiate sustainable and open access content provisions in subscription contracts. Both at the consortia and institutional level, these groups are closely examining upcoming contract renewal/cancelation negotiations, and are building frameworks for new licensing terms of agreement to achieve sustainable prices and incorporate open access options.

\section{Future of open access}

In the present and future framework of open access, there are several areas of development to be aware of, and the trajectory in which they are moving to accomplish specific goals, albeit many are aspirational in nature.

\section{Defining types of open access}

One of the methods of ensuring content remains open access is by publishing in a stable open access journal, or by paying for an article to become open access through article processing charges. Bronze OA is a publication that may have been offered free by a vendor at one time (Emery et al., 2020). Gold OA is typically paid open access through APCs. Green OA is usually achieved by depositing an article preprint in an institutional repository, and Platinum/Diamond OA is an open 
access publication, which is truest in the sense of open access because it requires no fee. Creative Commons Licenses may also be applied to resources, which give creators more power to establish boundaries on how content may be "copied, distributed, edited, remixed, and built upon" (Creative Commons, 2017). Terminology is likely to change based upon publishing models and how open access stipulations are negotiated and designated between libraries and information vendors.

\section{The internet}

The Internet outside of traditional repositories shows promise and opportunities for open access. The Internet Archive's "Wayback Machine" allows users to view historical websites that have been preserved on a routine basis because they allow web crawling, which allows automatic systems to read and preserve their content. In addition, the Internet Archive, Project Gutenberg, and Google Books provide free access to a substantial amount of content. However, such Internet repositories have been subject to accusations of piracy. Google Books was brought to court for digitizing books still in copyright, but the case was ultimately dismissed due to Google's use of snippets of books, which falls under fair use laws (Meyer, 2015). However, Google Scholar does a great service in providing indexed data that can lead a user to publisher owned, or open access content. The DOAJ, the Directory of Open Access Books, the Directory of Open Access Repositories, and the Registry of Open Access Repositories also serve as great resources for locating open access content.

Conversely, the most egregious offender of copyright infringement and information piracy continues to be Sci-Hub, a repository of journal articles made freely available on the web without the obtaining the proper rights to publish the content. It is contentious as some scholars view this as an invaluable tool for obtaining articles that are inaccessible due to expense or lack of a library subscription to the content. Other entities such as businesses view this activity as piracy and, therefore profit loss. Universities view Sci-Hub as a security threat (Anderson et al., 2020), as most articles are illegally obtained through phishing scams to acquire user credentials, and risk massive downloads of journals from their institutions. Access may be shut off because of security breaches, and piracy of information goes 
against many libraries' missions to provide information access legally. Whether viewed as Robin Hoods or pirates, these projects will continue to occur and be challenged, but are difficult to stop, as Sci-Hub and others operate outside U.S. legal jurisdiction.

\section{Open access tools}

In the wake of the serials crisis, several tools have emerged to help the open access movement. Unpaywall, the Open Access Button, Google Scholar, and Kopernio (although owned by the for-profit vendor, Clarivate), help direct users to open access content. For evaluating the worth of paid subscription resources, tools such as UnSub, Roam.plus, and Delta Think help combine usage, cost per use, open access content, and interlibrary loan prices to analyze the real worth of a subscription to a library. These tools help to identify what percentage of libraries subscription resources are open access, and are invaluable tools for not only identifying these journals, but tracking the amount of open access content available or diminishing over time. The data reports empower libraries to engage in one of the most notable present and continuing battlegrounds of open accesstransformative agreements.

\section{Transformative agreements and open access mandates}

A transformative agreement can best be described as a "contract agreement that seeks to shift [subscription] payment from a library to a publisher away from subscription- based reading and towards open access publishing" (Hinchliffe, 2019a). Within this agreement, there are "publish and read" and "read and publish" models. Read and publish agreements allow for reading the content (subscribing to a journal), but with negotiated costs included to make institutional publications open access. A publish and read model is a payment for each institutional article published, but users are able to read a journal without an additional cost. Read and publish agreements would be more beneficial with lower costs for high research article producing universities, whereas publish and read would be beneficial and lower cost for low research publishing universities (Hinchliffe, 2019a). Some universities have paid more than double their subscription costs 
under transformative agreements (Säll et al., 2020), so caution must be used as this strategy is pursued in the future.

Some of the most intriguing transformative aspirational initiatives have been developed by cOAlition S and MIT Libraries. As mentioned in the introduction of this column, the MIT Framework for Publisher Contracts is a new model for open access negotiations. In this framework, no author will have to waive open access rights, relinquish copyright, publishers will deposit the publication in the institution's repository, text analysis will be allowed, preservation will be maintained through trusted archives, and pricing models will be transparent and sustainable (MIT Ad Hoc Task Force, 2020). Hundreds of libraries have endorsed these aspirational principles as potential negotiating stipulations in future contracts with information vendors. MIT has had minimal success (ACS Newsroom, 2020), with other larger publishers unwilling to yield to these radical demands (Song, 2020). However, many of the points in the framework are gaining in momentum, and if anything, open the conversation for libraries and institutions pushing back to retain ownership rather than signing copyrights to publishers or paying high APCs to make content open access.

Plan $\mathrm{S}$ is another intriguing open access strategy established by the European Research Council, in which all scholarly publications funded by public or private grants must be published in open access journals, platforms, or repositories without an embargo, beginning in 2021 (cOALition S, 2018). Also aspirational, this places burdensome requirements on scholars, who may not be able to find open access journals that suitably meet their discipline, and would prevent them from publishing in prestigious and widely read journals, or the journal of their choice unless funding organizations override Plan S requirements (Van Noorden, 2020). Regardless, this poses complications for small presses, who cannot afford to publish without monetary support through subscriptions. Most notably, APC charges have not been negotiated with a cap on prices (Hinchliffe, 2019b). This has been a failing for both transformative agreements in the United States and Plan S in Europe. This could potentially set up an environment for another serials crisis, where APCs are unsustainable instead of subscription costs. 


\section{Conclusion}

Covering the milestones of open access to the transformative agreements of the MIT Framework for Publisher Contracts and Plan S, open access has a tremendous amount of future potential for options and strategies to pursue with the goal of making information freely accessible to scholars. While many goals are feasible, some are currently aspirational and only time will tell if they succeed or fail. Open access' flexibility to change will continue to shape libraries' thinking and how we continue resource provision in the future.

\section{ORCID}

Margaret Mering http://orcid.org/00oo-0002-6142-4398

Casey D. Hoeve http://orcid.org/0000-0003-4837-8910

\section{References}

ACS Newsroom. (2020, March 19). American Chemical Society signs innovative North American open access agreement with MIT. American Chemical Society. https:// www.acs.org/content/acs/en/pressroom/newsreleases/2020/march/acs-signsinnovative-north-american-open-access-agreement-with-mit.html

Anderson, R., Boissy, R., \& Buttiker, S. M. (2020). Beyond Sci-Hub: Cyber challenges for the scholarly communications industry. Against the Grain, 32(3), 17-19.

cOALition S. (2018). What is cOALition S? https://www.coalition-s.org/about/ Creative Commons (2017). About the licenses: What our licenses do. https:// creativecommons.org/licenses/

Emery, J., Stone, G., \& McCracken, P. (2020). Techniques for electronic resource management: TERMS and the transition to open. American Library Association.

Hinchliffe, L. J. (2019a, April 23). Transformative agreements: A primer. The Scholarly Kitchen., https://scholarlykitchen.sspnet.org/2019/04/23/ transformativeagreements/

Hinchliffe, L. J. (2019b, February 11). Taking stock of the feedback on Plan S implementation guidance. The Scholarly Kitchen. https://scholarlykitchen. sspnet.org/2019/02/11/with-thousand-of-pages-of-feedback-on-the-plans-simplementation-guidance-what-themes-emerged-that-might-guide-next-steps/

Kwon, D. (2018, July 19). Universities in Germany and Sweden lose access to Elsevier journals. The Scientist. https://www.the-scientist.com/news-opinion/ universities-in-germany-and-sweden-lose-access-to-elsevier-journals-64522

McKenzie, L. (2019, March 01). UC Drops Elsevier. Inside Higher Ed. https://www.insidehighered.com/news/2019/03/01/ university-california-cancels-deal-elsevier-after-months-negotiations 
Meyer, R. (2015, October 20). After 10 years, Google Books is legal. The Atlantic. https://www.theatlantic.com/technology/archive/2015/10/ fair-use-transformative-leval-google-books/411058/

MIT Ad Hoc Task force on open access to MIT's research, MIT faculty committee on the Library System, and MIT Libraries. (2020, May 19). MIT Framework for Publisher Contracts. https://libraries.mit.edu/scholarly/publishing/framework/

Royster, P. (2016, March 14). A brief history of open access [Presentation]. Academic Activities Brown Bag Series, Love Library, University of Nebraska-Lincoln, Lincoln, NE, USA. https://digitalcommons.unl.edu/library talks/123/

Säll, J., Parmhed, S., \& Tovstiadi, E. (2020, March 10). Transformative agreements and their headaches: New roles for librarians [Presentation]. ER\&L Conference, Austin, TX, USA.

Schimmer, R., Geschuhn, K. K., \& Volger, A. (2015). Disrupting the subscription journal's business model for the necessary large-scale transformation to open access. Max Planck Society. https://doi.org/10.17617/1.3

Song, G. (2020, June 17). MIT ends negotiations with Elsevier. The Tech. https:// thetech.com/2020/06/17/elsevier-negotiations-ended .

SPARC*. (2020). Big deal knowledge base. https://sparcopen.org/our-work/ big-deal-knowledge-base/

Suber, P. (2009, February 09). Timeline of the open access movement. Open Access Timeline. http://legacy.earlham.edu/_peters/fos/timeline.htm

Suber, P. (2015, December 05). Focusing on open access to peer-reviewed research articles and their preprints. Open Access Overview. http://legacy.earlham.edu/ peters/fos/overview.htm

University of California Libraries. (2016). Pay it forward: Investigating a sustainable model of open access article processing charges for large North American research institutions. https://www.library.ucdavis.edu/wp-content/uploads/2018/11/ICIS-

UC-Pay-It-Forward-Final-Report.rev -7.18.16.pdf

Van Noorden, R. (2020, July 16). Open-access Plan S to allow publishing in any journal. Nature. https://doi.org/10.1038/d41586-020-02134-6 